\title{
High-flux PIM-1/PVDF thin film composite membranes for 1-butanol/water pervaporation
}

DOI:

10.1016/j.memsci.2017.02.008

\section{Document Version}

Accepted author manuscript

Link to publication record in Manchester Research Explorer

\section{Citation for published version (APA):}

Gao, L., Alberto, M., Gorgojo, P., Szekely, G., \& Budd, P. (2017). High-flux PIM-1/PVDF thin film composite membranes for 1-butanol/water pervaporation. Journal of Membrane Science, 529, 207-214.

https://doi.org/10.1016/j.memsci.2017.02.008

\section{Published in:}

Journal of Membrane Science

\section{Citing this paper}

Please note that where the full-text provided on Manchester Research Explorer is the Author Accepted Manuscript or Proof version this may differ from the final Published version. If citing, it is advised that you check and use the publisher's definitive version.

\section{General rights}

Copyright and moral rights for the publications made accessible in the Research Explorer are retained by the authors and/or other copyright owners and it is a condition of accessing publications that users recognise and abide by the legal requirements associated with these rights.

\section{Takedown policy}

If you believe that this document breaches copyright please refer to the University of Manchester's Takedown Procedures [http://man.ac.uk/04Y6Bo] or contact uml.scholarlycommunications@manchester.ac.uk providing relevant details, so we can investigate your claim.

\section{OPEN ACCESS}




\title{
High-flux PIM-1/PVDF thin film composite membranes for
}

\section{1-butanol/water pervaporation}

Lei Gao ${ }^{\mathrm{a}}$, Monica Alberto ${ }^{\mathrm{b}}$, Patricia Gorgojo ${ }^{\mathrm{b}}$, Gyorgy Szekely ${ }^{\mathrm{b}}$, Peter M. Budd ${ }^{\mathrm{a} *}$

${ }^{a}$ School of Chemistry, University of Manchester, Manchester M13 9PL, UK

${ }^{\mathrm{b}}$ School of Chemical Engineering and Analytical Science, University of Manchester, Manchester M13 9PL, UK

*Corresponding author email address: Peter.Budd@ manchester.ac.uk

\begin{abstract}
Membranes that enable the recovery of organic compounds from dilute aqueous solution are desired for applications such as biobutanol production. The polymer of intrinsic microporosity PIM-1 shows promise for organophilic separations and here it is incorporated into thin film composite (TFC) membranes in order to increase the flux of permeate.

Asymmetric polyvinylidene fluoride (PVDF) supports were prepared with pore sizes at the surface in the size range $25-55 \mathrm{~nm}$ and fractional surface porosities in the range $0.38-0.69$, as determined by atomic force microscopy (AFM). The addition of phosphoric acid to the PVDF dope solution helped to control the pore size and porosity. Supports were coated with PIM-1 to form TFC membranes with active layer thicknesses in the range 1.0-2.9 $\mu \mathrm{m}$. Membranes were tested for the pervaporation of a 1-butanol/water mixture $(5 \mathrm{wt} . \%)$. At $65^{\circ} \mathrm{C}$, values of total flux up to $9 \mathrm{~kg} \mathrm{~m}^{-2} \mathrm{~h}^{-1}$ were obtained, with separation factors up to 18.5 and values of pervaporation separation index (PSI) up to $112 \mathrm{~kg} \mathrm{~m}^{-2} \mathrm{~h}^{-1}$.
\end{abstract}

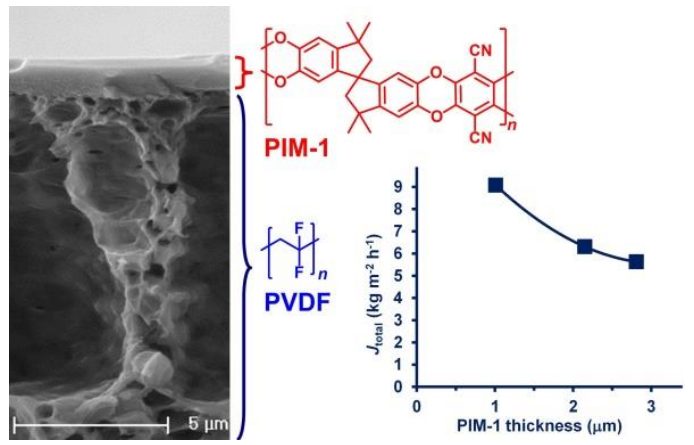

KEYWORDS

Pervaporation; Butanol; Thin film composite; Polymer of Intrinsic Microporosity 


\section{Introduction}

Pervaporation, in which evaporation occurs through a membrane, was first observed a century ago [1]. Hydrophilic pervaporation has found increasing use since the 1980s, when it was applied for the dehydration of alcohol [2]. Organophilic pervaporation, for the removal of organics from aqueous solution or for the separation of organic-organic mixtures, is much less well developed, but has attracted much attention in recent years. A promising application area is biobutanol production, where an economic and energy-efficient separation technique is needed to separate the product from the dilute fermentation broth [3-8].

A number of hydrophobic polymers have been investigated for organophilic pervaporation, including poly(dimethylsiloxane) (PDMS) [9], poly(octylmethyl siloxane) (POMS) [10-12], polyvinylidene fluoride (PVDF) [13], polyether-block-polyamide (PEBA) [14], poly(1-trimethylsilyl-1-propyne) (PTMSP) [15] and the polymer of intrinsic microporosity PIM-1 [16-19]. Inorganic membrane materials such as silicalite-1 [20] have also been employed. Improved performance can be achieved with mixed matrix membranes (MMMs) [6], such as PDMS/silicalite-1 [21], PDMS/ZIF-7 [22], PEBA/Zn(BDC)(TED) 0.5 [23] and PIM-1 with graphene-like fillers [24].

Polymers of intrinsic microporosity (PIMs) are glassy polymers that behave like microporous materials as defined by IUPAC (pore size $<2 \mathrm{~nm}$ ) [25]. Their backbones are composed of fused rings, so there are no single bonds about which rotation can occur, and they include sites of contortion, such as spiro-centres, which give rise to a macromolecular structure that twists and turns. They cannot pack efficiently in the solid state and thus possess high free volume. The prototypical PIM, referred to as PIM-1 (Figure 1), is a yellow, fluorescent, organophilic, membrane-forming polymer [16, 26]. In addition to its potential for organophilic pervaporation, it has been investigated for organic solvent nanofiltration [27-30] and gas separation [31-44], for which it helped to define the 2008 upper bound of performance for gas pairs such as $\mathrm{O}_{2} / \mathrm{N}_{2}, \mathrm{H}_{2} / \mathrm{N}_{2}, \mathrm{CO}_{2} / \mathrm{CH}_{4}$ and $\mathrm{CO}_{2} / \mathrm{N}_{2}$ [45]. The first application of PIM-1 to reach the marketplace is in an end-of-life indicator for organic vapour absorbing cartridges [46, 47]. 


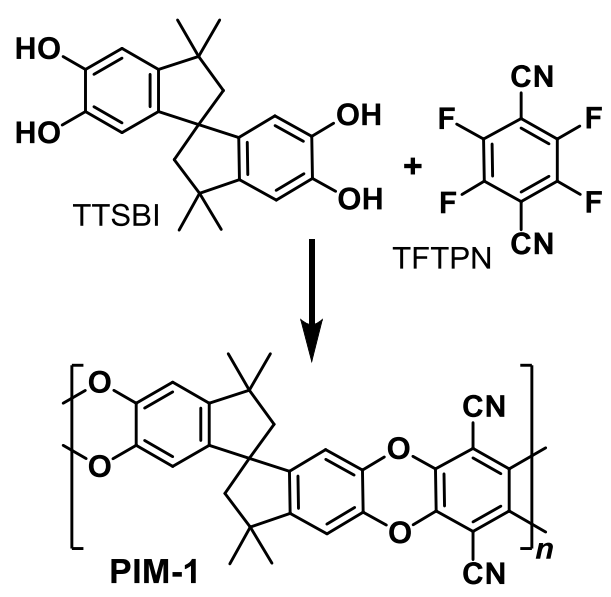

Fig. 1. Synthesis of PIM-1 from tetrahydroxy-3,3,3',3'-tetramethyl-1,1'-spirobisindane (TTSBI) and tetrafluoroterephthalonitrile (TFTPN). Reagents and conditions:

Dimethylacetamide, toluene, $\mathrm{K}_{2} \mathrm{CO}_{3}, 160{ }^{\circ} \mathrm{C}, 40 \mathrm{~min}$.

The potential of PIM-1 for organophilic pervaporation was recognised in the first publication concerning a PIM-1 membrane [16], which reported results for pervaporation of phenol/water mixtures, demonstrating a tenfold enrichment of phenol in the permeate. Subsequent studies looked at pervaporation of ethanol/water [17] and butanol/water [18] mixtures, and the use of pervaporation for the removal of volatile organic compounds (VOCs), such as ethyl acetate, dimethyl ether and acetonitrile, from wastewater [19]. MMMs of PIM-1 with silicalite-1 [48] and graphene-like fillers [24] have also been investigated for pervaporation. All these studies were carried out on free-standing membranes with thicknesses in the range $30-110 \mu \mathrm{m}$.

The performance of a pervaporation membrane is characterized by its productivity and its selectivity. Productivity may be expressed in terms of flux, which generally increases as membrane thickness decreases, so a very thin membrane is desirable to maximise flux. However, a membrane must also be mechanically robust for practical application. Thus, commercial membranes usually have an asymmetric structure, with a thin active layer on the surface of a macroporous support. The active layer may be of the same material as the support (integrally skinned), or a different material (thin film composite). The aim of the present research was to generate thin film composite (TFC) membranes with a PIM-1 active layer for organophilic pervaporation. 
Ideally, the macroporous support in a TFC membrane would merely provide mechanical stability and would not influence the transport properties. However, in practice, the nature of the support may have a profound influence on the performance [49]. TFC membranes of PIM-1 on polyacrylonitrile (PAN) supports have successfully been applied in organic solvent nanofiltration [27, 30]. However, when PIM-1/PAN TFC membranes were investigated for organophilic pervaporation [50], the relatively hydrophilic support was found to dominate the behaviour. In phenol/water pervaporation, with the active PIM-1 layer of the TFC on the feed side, the flux was reduced, compared to a free-standing membrane, and the separation shifted from organophilic to hydrophilic. This could be attributed to condensation of water within the pores of the PAN support. It was found that organophilic behaviour could be recovered by turning the membrane around, so that the support was on the feed side. However, for both phenol/water and butanol/water pervaporation, PIM-1/PAN TFC membranes gave lower selectivities than those that could be achieved with free-standing PIM-1 membranes. Thus, the present work sought to develop tailored supports based on a more hydrophobic polymer, PVDF.

PVDF is an ideal candidate for use as a polymeric support in TFC membranes, because of its excellent thermal and chemical stability. PVDF has been used as the support material for pervaporation membranes with active layers of PDMS [49, 51-53], PDMS/ZIF-7 [22], silica-filled PTMSP [54] and PEBA/Zn(BDC)(TED) 0.5 [23]. PVDF substrates have been utilised for TFC membranes not only in flat-sheet form, but also in hollow fibre form [55]. Macroporous supports are prepared by a phase-inversion process, most commonly brought about by immersion of a polymer solution in a non-solvent. A variety of non-solvent additives, such as glycerol, ethylene glycol, polyethylene glycol, lithium chloride, methanol and phosphoric acid [56-58], may be included in the polymer solution to control the porosity of the resulting film. Phosphoric acid can be a particularly effective additive for improving flux [58-62] and so was utilised in the present work in order to tailor the support. 


\section{Experimental}

\subsection{Materials}

PIM-1 was prepared as described by Du et al. [63]. Characterization by multi-detector gel permeation chromatography (Viscotek VE2001 GPC solvent/sample module with two PLgel mixed-B columns and Viscotek TDA302 triple detector array, $\mathrm{CHCl}_{3}$ eluent with a flow rate of $1 \mathrm{ml} \mathrm{min}^{-1}$, analysis by OmniSEC software) gave weight-average molar mass $M_{\mathrm{w}}$ $=186,000 \mathrm{~g} \mathrm{~mol}^{-1}$ and polydispersity $M_{\mathrm{w}} / M_{\mathrm{n}}=2.5$.

Polyvinylidene fluoride (PVDF, $M_{\mathrm{w}} \sim 5.34 \times 10^{5} \mathrm{~g} \mathrm{~mol}^{-1}$ ) was purchased from SigmaAldrich. Polypropylene (PP) non-woven fabric was purchased from Freudenberg Filtration Tech Ltd (Germany). Dimethylacetamide (DMAC), chloroform, 1-butanol, phosphoric acid and formaldehyde (37 wt\% in water) were all supplied by Sigma-Aldrich. A commercial PDMS pervaporation membrane was kindly provided by Pervatech BV (The Netherlands).

\subsection{Membrane preparation}

Free-standing PIM-1 membranes were prepared by solution casting. 0.14 g PIM-1 powder was dissolved in $10 \mathrm{ml}$ chloroform with mechanical stirring for $24 \mathrm{~h}$. Then the solution was cast in a glass petri dish (6.9 cm diameter). The film was dried for 2 days under a nitrogen atmosphere at room temperature.

For the preparation of PVDF supports, dope solutions were prepared of PVDF in DMAC at concentrations of 18, 20 and $22 \mathrm{wt} . \%$. The dope solutions were mechanically stirred at $70{ }^{\circ} \mathrm{C}$ for $10 \mathrm{~h}$ and subsequently left overnight to remove bubbles. Homogeneous dope solutions (normally $25 \mathrm{ml}$ ) were cast on PP non-woven fabric at a coating velocity of $0.05 \mathrm{~m} \mathrm{~s}^{-1}$, using an automatic film applicator (Elcometer 4340) with a doctor blade set to a casting gap of $250 \mu \mathrm{m}$. After casting, the polymer films were immediately immersed in distilled water at room temperature for $1 \mathrm{~h}$ to solidify the support thoroughly. The PVDF supports were stored in dilute formaldehyde solution (1 wt.\%) until use, in accordance with the procedure of Claes et al. [54]. Supports prepared from 18, 20 and $22 \mathrm{wt}$.\% PVDF solution are referred to as PVDF 18, 20 and 22, respectively. 
PVDF supports were also fabricated with phosphoric acid as an additive to control the porosity and pore size distribution. Dope solutions were prepared of $18 \mathrm{wt}$ \% PVDF with 3 and $5 \mathrm{wt} . \%$ phosphoric acid in DMAC, and the above procedure followed. Supports prepared with 3 and 5 wt.\% phosphoric acid are referred to as PVDF 18-A3 and 18-A5, respectively.

TFC membranes of PIM-1 on PVDF supports were prepared by dip-coating. Solutions were prepared of PIM-1 in chloroform at concentrations of 2, 3 and 4 wt.\%. A PVDF support was dried under vacuum at ambient temperature for $1 \mathrm{~h}$, then a piece $(63 \times 45 \mathrm{~mm})$ was fixed on a glass slide and the edge sealed with aluminium tape, to ensure only the PVDF-coated side of the support came into contact with PIM-1 solution. A KSV NIMA dip-coater was used to immerse the support vertically into the PIM-1 solution with a constant speed of 100 $\mathrm{mm} \mathrm{min}^{-1}$; it was kept immersed for $2 \mathrm{sec}$, then removed at $100 \mathrm{~mm} \mathrm{~min}^{-1}$. The membrane was then dried for $10 \mathrm{~min}$ in ambient air for solidification to occur. Membranes were stored under ambient conditions, and dried in a vacuum desiccator for $1 \mathrm{~h}$ before use.

\subsection{Membrane characterization}

For analysis of morphology, cross sections of PVDF supports and PIM-1/PVDF TFC membranes were examined by a Field Emission Gun Scanning Electron Microscope (FEGSEM Philips XL30) at an acceleration voltage of $10 \mathrm{keV}$. All the membrane sample were frozen in liquid nitrogen, fractured for cross section imaging, then coated with a Au layer ( 4 $\mathrm{nm})$ to prevent charging under the electron beam.

The surface morphology of PVDF supports was examined by Atomic Force Microscopy (AFM) (Bruker Multimode), with a scanning area of $5 \times 5 \mu \mathrm{m}$ and a scanning rate of $1.0 \mathrm{~Hz}$. 2D surface scanning image, 3D surface structure and roughness parameters were computed automatically using Nanoscope Analysis software. The pore size distribution, average pore size and surface porosity of PVDF supports were determined using ImageJ software. The software converted the AFM 2D surface image to a black and red image, in which red spots represented pores on the support surface; the total red area in a specific area was computed [64]. This was repeated eight times for each sample and an average value obtained. 
Water contact angles of PVDF supports were measured by a Theta optical tensiometer (Biolin Scientific). A droplet of deionized water was placed on a dry membrane sample; the static sessile drop method was applied and data were analyzed by OneAttension software. The angle formed between the liquid and solid interface was determined by a high-resolution camera. Each sample was tested eight times and an average value obtained.

\subsection{Pervaporation}

A batch pervaporation system (Figure 2) was constructed in-house. A circular disk (diameter $1.8 \mathrm{~cm}$ ) was cut from a membrane sheet, fixed in the membrane cell and sealed with a Viton O-ring. Subsequently, 5 wt.\% butanol/water feed solution was prepared and kept at a constant temperature by heating with a water bath. Most experiments were carried out at $65{ }^{\circ} \mathrm{C}$, but further experiments were undertaken for one membrane (PVDF 18-A3 dip-coated with 2 wt.\% PIM-1 solution) at 40 and $50{ }^{\circ} \mathrm{C}$, to investigate the effect of feed temperature. The pervaporation was operated using vacuum as driving force, keeping the pressure on the permeate side at 0.2 mbar. The permeate vapour was cooled by liquid nitrogen and collected in a trap. Permeate collected during the first hour was discarded, due to the non-equilibrium condition. Then, the pervaporation was run another $2 \mathrm{~h}$. The total flux, $J_{\text {total }}$, was calculated using

$$
J_{\text {total }}=\frac{m}{A t}
$$

where $m$ is the mass of permeate collected over time $t$ for a membrane of area $A$. For each type of membrane, measurements were repeated on five membrane discs, to obtain an average and standard deviation. Total flux was broken down into partial fluxes, $J_{i}$, for each component in the mixture, on the basis of the permeate composition. Flux depends on the driving force for permeation, and thus on the conditions of the experiment, and also on the thickness, $l$, of the membrane. To obtain properties that relate primarily to the membrane material, partial fluxes may be related to permeabilities for each component,

$$
P_{i}=\frac{J_{i} l}{\left(f_{i, \mathrm{f}}-f_{i, \mathrm{p}}\right)}
$$


where $f_{i, \mathrm{f}}$ and $f_{i, \mathrm{p}}$ are fugacities or partial pressures of component $i$ in the feed and permeate, respectively.

Butanol concentrations were determined by gas chromatography (GC). The butanolwater sample was diluted with acetone to form a single liquid phase. Analysis was performed using an Agilent 7820A gas chromatography system with a flame ionization detector, which responds to butanol and acetone, but not to water. The concentration of butanol in the diluted sample was determined from the area of the butanol peak using a calibration line from measurements of butanol/acetone/water mixtures of known composition (see supplementary information). The composition of the original sample was then calculated on the basis of the known dilution. The column was a PoraPLOT Q-HT $(10 \mathrm{~m} \times 0.32 \mathrm{~mm} \times 20 \mu \mathrm{m})$. Helium was used as carrier gas with a constant flow rate of $1.2 \mathrm{~mL} \mathrm{~min}^{-1}$. The ion source was set at a temperature of $190{ }^{\circ} \mathrm{C}$. The oven temperature programming was initially $175{ }^{\circ} \mathrm{C}$, kept isothermal for $2 \mathrm{~min}$, ramped at $15{ }^{\circ} \mathrm{C} \min ^{-1}$ up to $200{ }^{\circ} \mathrm{C}$, and isothermal again at this temperature for $2.5 \mathrm{~min}$. The injection volume was $2 \mu \mathrm{L}$, applying a split ratio of $60: 1$. The scanning time was $6.1 \mathrm{~min}$.

Separation factors were calculated using

$$
\beta=\frac{\left(Y_{\text {butanol }} / Y_{\text {water }}\right)}{\left(X_{\text {butanol }} / X_{\text {water }}\right)}
$$

where $Y_{\text {butanol }} / Y_{\text {water }}$ is the weight ratio of butanol to water in the permeate and $X_{\text {butanol }} / X_{\text {water }}$ is the corresponding ratio in the feed. Alternatively, selectivity may be expressed as a ratio of permeabilities.

$$
\alpha=\frac{P_{\text {butanol }}}{P_{\text {water }}}
$$

There is generally a trade-off between productivity and selectivity. The overall performance of a membrane is indicated by a pervaporation separation index [65]

$$
\mathrm{PSI}=J_{\mathrm{total}}(\beta-1)
$$


which is zero if there is no separation, either because there is no flux $\left(J_{\text {total }}=0\right)$ or because there is no separation $(\beta=1)$.

A further experiment was conducted with one membrane (PVDF 18 dip-coated with 4 wt.\% PIM-1 solution) to monitor the pervaporation performance over time at $65^{\circ} \mathrm{C}$.

Pervaporation was run for $1 \mathrm{~h}$, then the membrane transferred to fresh $5 \mathrm{wt} . \%$ butanol solution ( $7.5 \mathrm{~g}$ butanol, $142.5 \mathrm{~g}$ water), and pervaporation conducted for $5 \mathrm{~h}$, collecting the permeate and a sample of the feed for analysis after each hour.

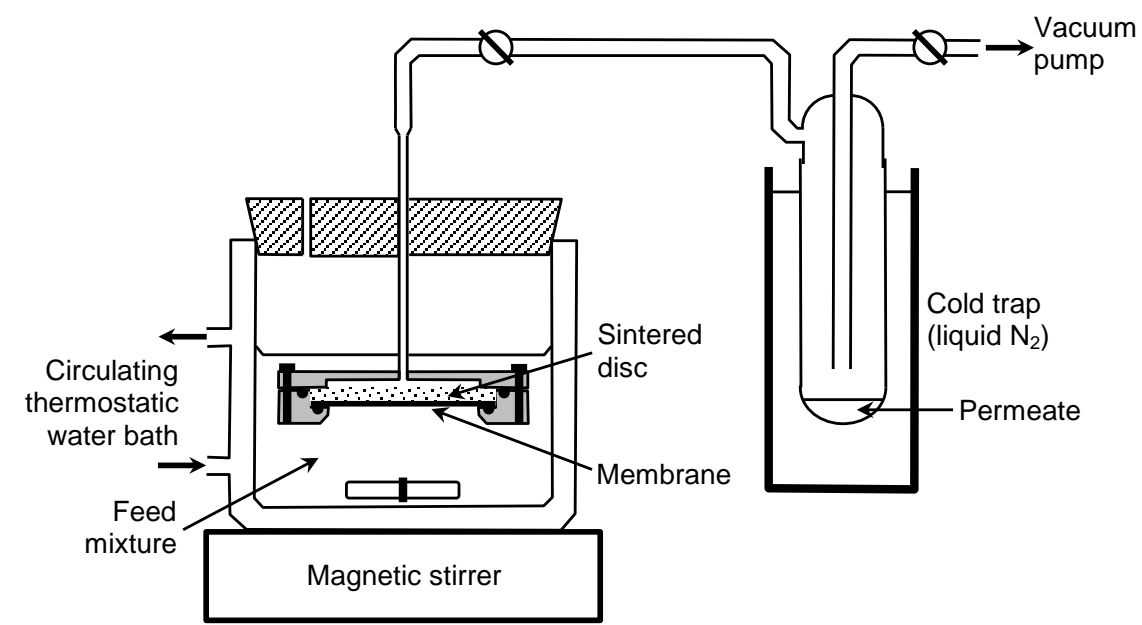

Fig. 2. Schematic illustration of batch pervaporation apparatus. 


\section{Results and Discussion}

\subsection{PVDF supports}

PVDF supports were prepared on PP non-woven fabric using DMAC dope solutions with three different PVDF concentrations (18, 20 and 22 wt.\%) and, for 18 wt.\% PVDF, with phosphoric acid as a non-solvent additive at 3 and $5 \mathrm{wt} \%$ (Table 1). Cross-sectional SEM showed that the PVDF was successfully coated on the non-woven fabric (Fig. 3(a)), and that PVDF layers were formed of 40-55 $\mu \mathrm{m}$ thickness with finger-like macropores (Fig. 3(b)).

Table 1. Composition of dope solution, average pore size, fractional surface porosity $\left(f_{\mathrm{p}}\right)$, average roughness $\left(R_{\mathrm{a}}\right)$, peak to valley roughness $\left(R_{\mathrm{z}}\right)$ and root mean square roughness $\left(R_{\mathrm{q}}\right)$ from atomic force microscopy, and water contact angle for PVDF supports.

\begin{tabular}{|c|c|c|c|c|c|c|c|c|}
\hline \multirow[b]{2}{*}{$\begin{array}{l}\text { PVDF } \\
\text { support }\end{array}$} & \multicolumn{2}{|c|}{ Dope solution } & \multicolumn{5}{|c|}{ Atomic force microscopy } & \multirow[b]{2}{*}{$\begin{array}{c}\text { Water contact } \\
\text { angle } \\
\text { (degrees) }\end{array}$} \\
\hline & $\begin{array}{l}\text { PVDF } \\
\text { (wt. \%) }\end{array}$ & $\begin{array}{l}\mathrm{H}_{3} \mathrm{PO}_{4} \\
\text { (wt. } \% \text { ) }\end{array}$ & $\begin{array}{c}\text { Average } \\
\text { pore size } \\
(\mathrm{nm})\end{array}$ & $f_{\mathrm{p}}$ & $R_{\mathrm{a}}$ & $R_{\mathrm{z}}$ & $R_{\mathrm{q}}$ & \\
\hline 18 & 18 & 0 & 54.5 & 0.518 & 52.8 & 66.3 & 46.1 & 84 \\
\hline 18-A3 & 18 & 3 & 43.2 & 0.693 & 47.5 & 59.5 & 43.3 & 80 \\
\hline 18-A5 & 18 & 5 & 25.3 & 0.625 & 33.8 & 42.5 & 28.4 & 73 \\
\hline 20 & 20 & 0 & 44.8 & 0.473 & 46.6 & 56.6 & 43.7 & 79 \\
\hline 22 & 22 & 0 & 28.6 & 0.376 & 41.5 & 50.5 & 30.6 & 76 \\
\hline
\end{tabular}


(a)
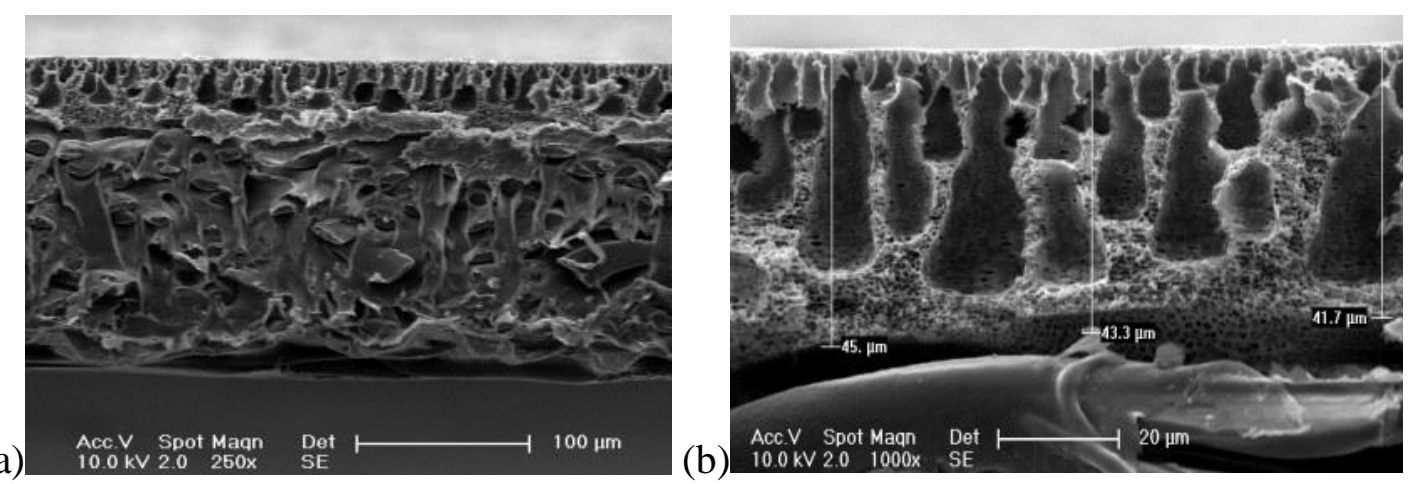

(c)

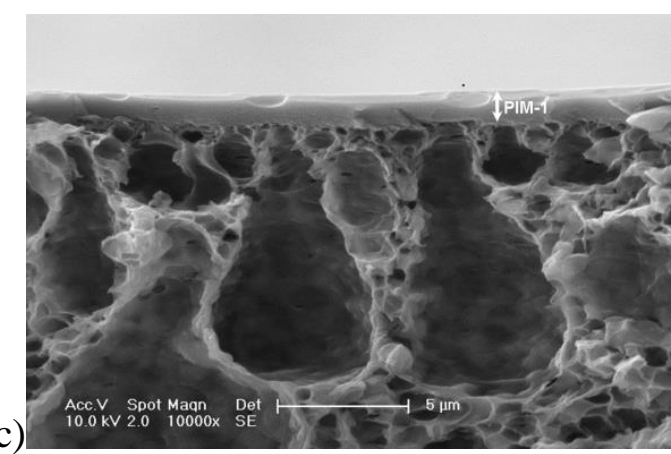

Fig. 3. Representative scanning electron micrographs of cross sections of (a) PVDF 18 on PP non-woven fabric, (b) the same support at higher magnification, showing finger-like macropores and (c) PIM-1 thin film (coated from 2 wt.\% solution) on PVDF 18.

The surface morphology of the PVDF supports was investigated by AFM (See supplementary information for images). Average pore sizes and values of surface porosity, from analysis of the surface images, are included in Table 1. It can be seen that increasing the PVDF concentration in the dope solution decreases both the average pore size and surface porosity in the final support. However, addition of phosphoric acid at $3 \mathrm{wt} . \%$ enhances surface porosity while decreasing the average pore size; this is desirable for TFC membranes, since high surface porosity increases flux while a relatively small pore size helps to ensure a defect-free coating of the active layer. A higher concentration of acid (5 wt.\%) decreases pore size further, but with a slight loss of surface porosity. Both thermodynamic and kinetic factors may contribute to the observed effect of phosphoric acid as a non-solvent additive in the PVDF solution [62]. From the thermodynamic point of view, a non-solvent additive shifts the cloud point curve in the phase diagram, as a consequence of which less water is needed to bring about phase inversion under given conditions [66]. This leads to faster demixing and a more porous structure. From the kinetic point of view, an additive may increase the viscosity of the solution, which can slow down phase separation [67]. The latter effect is likely to 
dominate at higher additive concentrations.

Distributions of pore size are provided in the supplementary information. Surface roughness is indicated by the roughness parameters, from AFM topographical images, tabulated in Table 1. Smaller surface pore size generally corresponds to a smoother surface (smaller roughness parameters) [68]. This in turn leads to a slightly more hydrophilic surface [64], as indicated by the water contact angles in Table 1.

\subsection{PIM-1/PVDF TFC membranes}

PIM-1/PVDF TFC membranes were prepared by dip-coating PVDF supports with solutions of PIM-1 in chloroform at concentrations of 2, 3 and 4 wt.\%. Thin PIM-1 active layers were formed on the supports (Fig. 3(c)). For the same dip-coating conditions, higher PIM-1 concentrations gave thicker PIM-1 layers, as might be expected. For each support, TFC membranes were obtained with active layer thicknesses in the ranges 1.0-1.2, 2.0-2.2 and 2.7-2.9 $\mu \mathrm{m}$ for 2, 3 and $4 \mathrm{wt} . \%$, respectively. Active layer thicknesses from SEM analysis are given for each membrane in the supplementary information.

\subsection{Pervaporation performance}

The PIM-1/PVDF TFC membranes were tested for the pervaporation of a 1butanol/water mixture ( $5 \mathrm{wt} . \%$ 1-butanol) at a temperature of $65^{\circ} \mathrm{C}$, and one membrane was also tested at temperatures of 40 and $50{ }^{\circ} \mathrm{C}$. For all the TFC membranes, a significant enhancement in 1-butanol concentration was achieved, with permeate concentrations in the range 28-49 wt.\% 1-butanol, representing separation factors in the range 7.5-18.5. High values of total flux, up to $9 \mathrm{~kg} \mathrm{~m}^{-2} \mathrm{~h}^{-1}$, were obtained. The best of the membranes (TFC PIM1 from a 2 wt.\% solution on PVDF 18-A3) gave a PSI of $112 \mathrm{~kg} \mathrm{~m}^{-2} \mathrm{~h}^{-1}$ at $65{ }^{\circ} \mathrm{C}$. Details of the pervaporation results are given in the supplementary information.

For comparison, a free-standing PIM-1 membrane (thickness $27 \mu \mathrm{m}$ ) and a composite membrane with a PDMS active layer were tested under identical conditions, with the results shown in Table 2. As expected, PIM-1/PVDF TFC membranes gave significantly higher fluxes than the free-standing PIM-1 membrane, albeit with a slight loss of selectivity. Both flux and selectivity were better than for a PDMS composite membrane under the same 
conditions. Also included in Table $\mathbf{2}$ are representative data from the literature, obtained under a variety of conditions. The fluxes achieved here are higher than for most membranes reported in the literature, with the notable exception of VITO 1, a TFC membrane of PTMSP filled with hydrophobic silica, on a PVDF support [15]. 
Table 2. Butanol/water pervaporation performance of various membranes: active layer thickness, feed temperature, feed composition, total flux $\left(J_{\text {total }}\right)$, separation factor $(\beta)$ and pervaporation separation index (PSI).

\begin{tabular}{|l|c|c|c|c|c|c|c|}
\hline \multicolumn{1}{|c|}{ Membrane } & $\begin{array}{c}\text { Active layer } \\
\text { thickness } \\
(\mu \mathrm{m})\end{array}$ & $\begin{array}{c}\text { Feed } \\
\text { temperature } \\
\left({ }^{\circ} \mathrm{C}\right)\end{array}$ & $\begin{array}{c}\text { Feed } \\
\text { composition } \\
(\mathrm{wt} \% \text { butanol) }\end{array}$ & $\begin{array}{c}J_{\text {total }} \\
\left(\mathrm{kg} \mathrm{m}^{-2} \mathrm{~h}^{-1}\right)\end{array}$ & $\begin{array}{c}\text { PSI } \\
\left(\mathrm{kg} \mathrm{m}^{-2} \mathrm{~h}^{-1}\right)\end{array}$ & $\begin{array}{c}\text { Reference } \\
\text { This work }\end{array}$ \\
\hline PIM-1/PVDF 18-A3 (2\% PIM-1) & 1.0 & 65 & 5 & 9.08 & 13.3 & 112 \\
\hline PIM-1 free-standing & 27 & 65 & 5 & 1.85 & 19.6 & 34 & This work \\
\hline PDMS supported (Pervatech) & - & 65 & 5 & 5.25 & 9.9 & 47 & This work \\
\hline PDMS/ceramic hollow fibre & 10 & 40 & 1 & 1.28 & 43 & 54 & {$[9]$} \\
\hline PDMS/PE/brass & 65 & 37 & 2 & 0.132 & 32 & 4 & {$[69]$} \\
\hline ZIF-7/PDMS MMM on PVDF & 20 & 60 & 5 & 1.689 & 66 & 110 & {$[22]$} \\
\hline PDMS Pervap 4060 (Sulzer) & - & 50 & 5 & 3.4 & 39 & 129 & {$[15]$} \\
\hline Silica-filled PTMSP/PVDF (VITO 1) & 2.4 & 50 & 5 & 9.5 & 104 & 978 & {$[15]$} \\
\hline PTMSP free-standing & 22 & 70 & 6 & 2.097 & 41 & 84 & {$[70]$} \\
\hline Surface-modified PVDF & 120 & 50 & 7.5 & 4.126 & 6.4 & 22 \\
\hline PEBA/ceramic hollow fibre & 3.5 & 40 & 1 & 2.011 & 20 & 40 \\
\hline Norbornene block copolymer on PAN & 1.3 & 60 & 1 & 4.300 & 21 & 86 \\
\hline HBPE-HTPB-PU on PAN & 31 & 70 & 3.42 & 0.3207 & 10.2 & {$[14]$} \\
\hline
\end{tabular}


For a given support, the total flux, $J_{\text {total }}$, increases with decreasing thickness of the PIM-1 active layer, as can be seen in Fig. 4(a). The same trend is observed for the water flux and, to a lesser extent, the butanol flux. Fig. 4(a) also shows that the flux depends on the support. The primary way in which the support may influence flux is through its surface porosity, as low surface porosity reduces the effective membrane area. This can be taken into account by dividing measured fluxes by the fractional surface porosity, $f_{\mathrm{p}}$, of the support, derived from AFM measurements. The flux may be further normalized for the thickness of the active layer, by multiplying by active layer thickness, $l$. Values of $J_{\text {total }} l / f_{\mathrm{p}}$ and $J_{\text {butanol }} l / f_{\mathrm{p}}$ are plotted in Fig. 4(b). It can be seen that different supports give results in very reasonable agreement when the surface porosity is taken into account. However, the thicknessnormalised flux decreases with decreasing active layer thickness, over the thickness range 1-3 $\mu \mathrm{m}$. Thus, although the membranes with the thinnest active layers show the highest fluxes, they are not as high as might be expected on the basis of the performance of TFC membranes with thicker active layers. The thickness-dependence does not extrapolate linearly to very much thicker, free-standing membranes. Extrapolation of the data in Fig. 4(b) to $27 \mu \mathrm{m}$ (the thickness of the free-standing PIM-1 membrane of Table 2) gives a normalised total flux of $147 \mathrm{~kg} \mathrm{~m}^{-2} \mathrm{~h}^{-1} \mu \mathrm{m}$, nearly three times higher than the experimental value of $50 \mathrm{~kg} \mathrm{~m}^{-2} \mathrm{~h}^{-1}$ $\mu \mathrm{m}$.

The decrease in the thickness-normalised flux as the thickness of the active layer decreases may relate either to the process or to the material. A pervaporation process may be affected by concentration polarization [74], the build-up of a boundary layer in the feed, close to the membrane surface, that is enriched in the less permeable component. This can be particularly pronounced for thin films that exhibit high fluxes, reducing the flux compared to that which would be observed in the absence of the effect. Material properties may also depend on thickness, particularly for a high free volume, glassy polymer such as PIM-1, which relies on frustrated packing for its free volume and thus its permeation properties. The conformational freedom of a polymer chain is perturbed by a surface or other boundary, and surface effects become more pronounced the thinner the film. In thin films, not only may the properties differ from those in the bulk of a thick film, but physical aging processes may also be much more rapid [75]. For PIM-1, ultrathin films (down to $35 \mathrm{~nm}$ thickness) on polyacrylonitrile (PAN) and alumina supports have been investigated for organic solvent nanofiltration [30]. In that work, a decrease in permeability was observed for film thicknesses 
below $140 \mathrm{~nm}$, which was attributed to enhanced packing in ultrathin films. In the present work, under the conditions of the pervaporation experiments, a dependence on film thickness is seen at greater thicknesses $(1-3 \mu \mathrm{m})$.
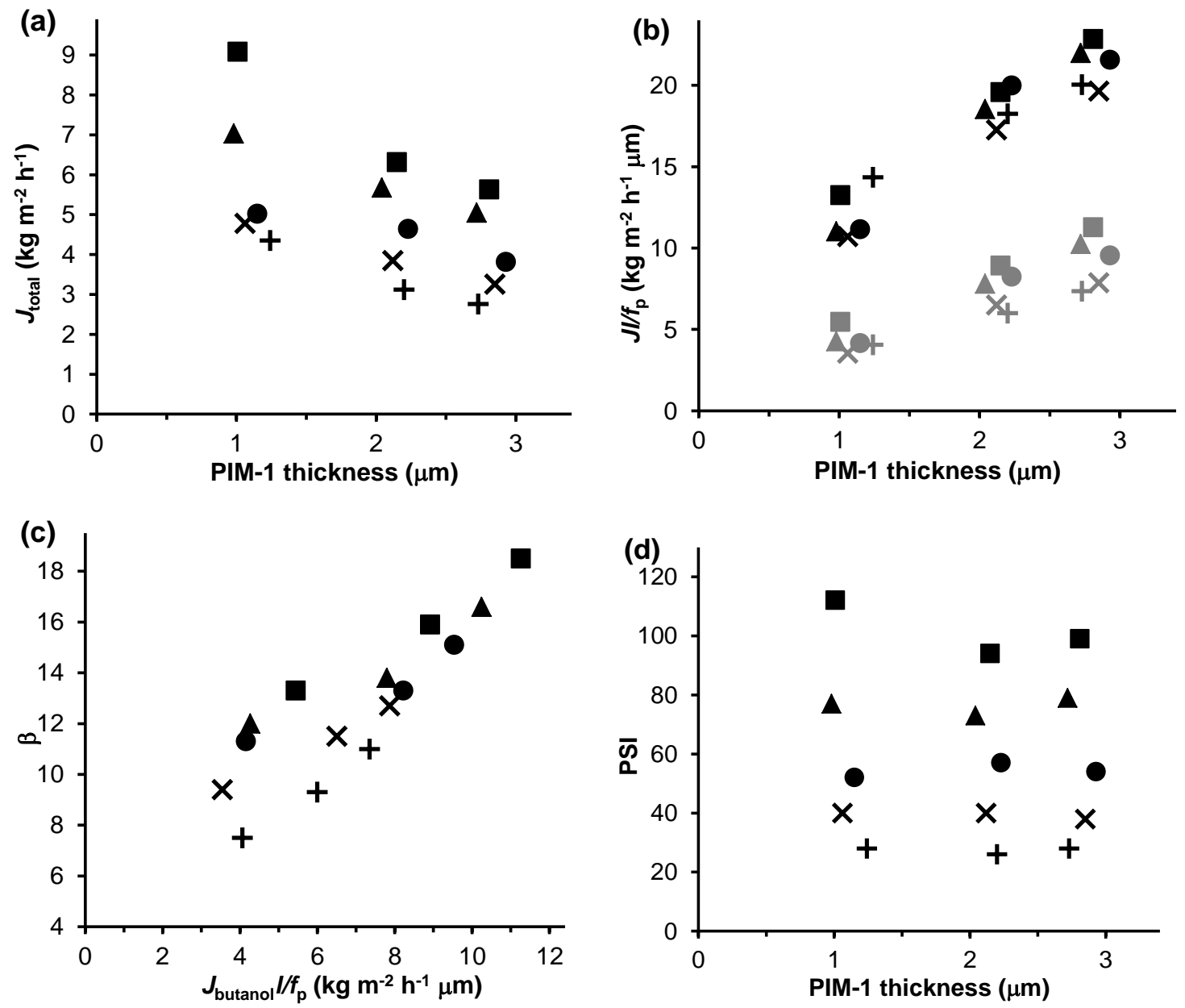

Fig. 4. Dependence of (a) total flux on PIM-1 thickness, (b) $J_{\text {total }} l / f_{\mathrm{p}}$ (black symbols) and $J_{\text {butanol }} l / f_{\mathrm{p}}$ (grey symbols) on PIM-1 thickness, (c) separation factor on $J_{\text {butanol }} l / f_{\mathrm{p}}$ and (d) pervaporation separation index on PIM-1 thickness for TFC membranes of PIM-1 on PVDF 18 (@), PVDF 18-A3 (ם), PVDF 18-A5( $\mathbf{\Delta})$, PVDF $20(\times)$ and PVDF $22(+)$.

The separation factor, $\beta$, increases with increasing butanol flux, normalised for PIM-1 thickness and surface porosity, as can be seen in Fig. 4(c). The separation factor represents the ability to concentrate up a dilute butanol solution. However, under the conditions of these experiments, butanol fluxes are lower than water fluxes for all the PIM-1/PVDF TFC membranes studied. The high water content of the feed provides a high driving force for water transport. It should be noted that pure water does not pass through a PIM-1 membrane, but water transport is possible when an alcohol is present [76]. As has been discussed by 
Rozicka et al. [77], there is a distinction between the apparent properties of a membrane, in terms of the separation that can be achieved under given conditions, and the intrinsic properties, which relate to the permeabilities of different components through the membrane.

Taking both flux and separation factor into account, Fig 4(d) shows that the support has a profound influence on the values of PSI that are achieved. PVDF18-A3 clearly outperforms the other supports studied here. This demonstrates that optimization of the support is as critical as selection of the active layer in developing composite membranes for applications such as butanol purification.

The temperature dependences of flux, separation factor and PSI are shown in Fig. 5 for one membrane. Flux and separation factor increase with increasing temperature, both leading to a significant enhancement in PSI at higher tmeperature.
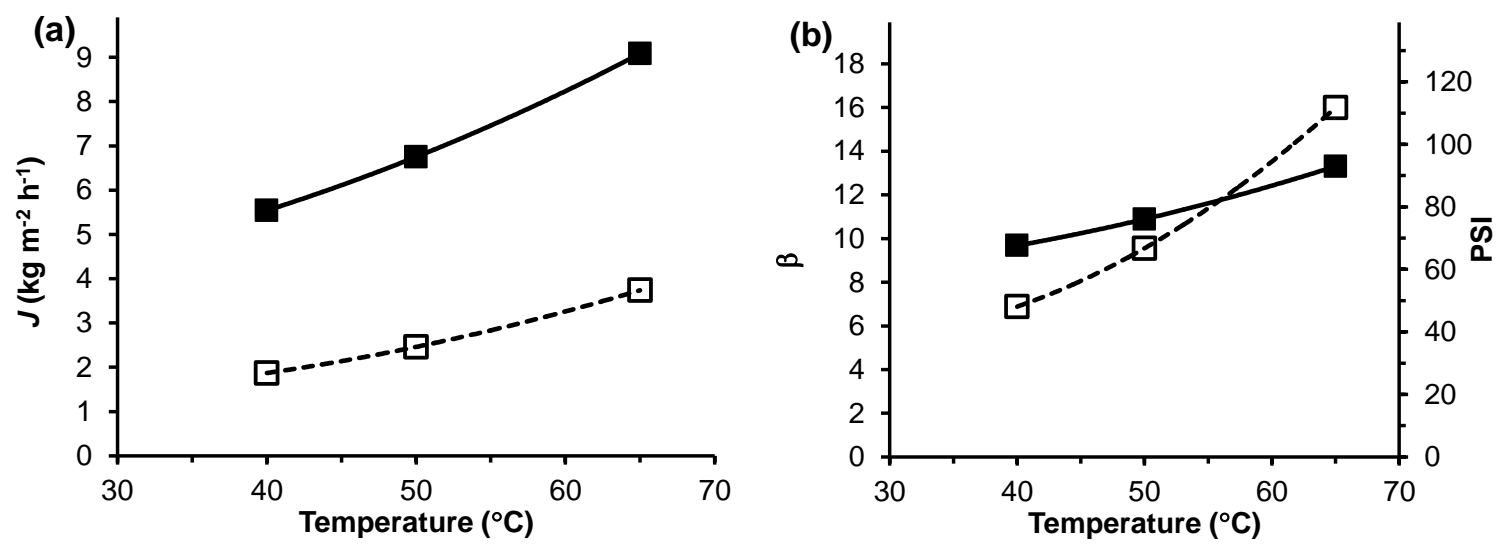

Fig. 5. Dependence on temperature of (a) total flux ( $\square$ ) and butanol flux ( $\square$ ), and (b) separation factor ( $\boldsymbol{\square}$, left axis) and PSI ( $\square$, right axis), for pervaporation of a $5 \mathrm{wt} \% 1$ butanol aqueous solution with a TFC membrane of PVDF 18-A3 dip-coated with 2 wt.\% PIM-1 solution.

Fig. 6 shows the results of an experiment in which the pervaporation performance was monitored over a $5 \mathrm{~h}$ period, sampling the feed and collecting the permeate after each hour. This enables the mass balance to be checked for the pervaporation process. Inevitably, there are small losses of butanol associated with each sampling step, but on average this is just $1.2 \%$ of the original butanol per step. Within acceptable error, butanol lost from the feed is accounted for in the permeate and in the samples of feed taken for analysis. 


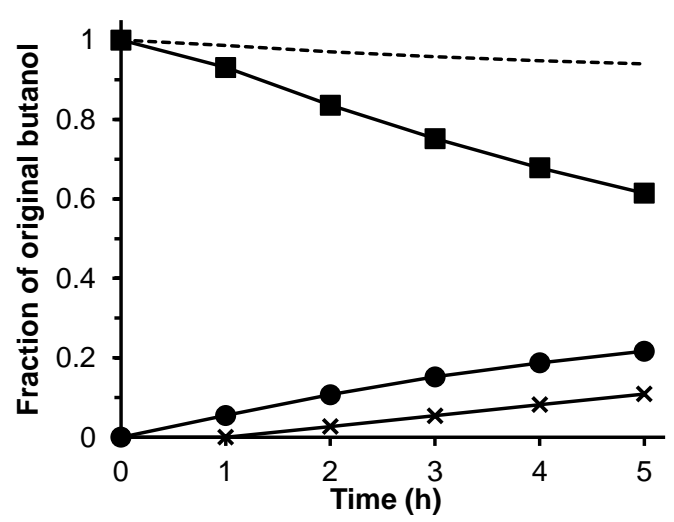

Fig. 6 Dependence on time of fraction of original butanol in the feed ( $\boldsymbol{\square})$, fraction permeated (O), fraction in samples of feed taken for analysis $(x)$ and the sum of these (dashed line), for pervaporation of a $5 \mathrm{wt} \%$ 1-butanol aqueous solution at $65^{\circ} \mathrm{C}$ with a TFC membrane of PVDF 18 dip-coated with 4 wt.\% PIM-1 solution.

\section{Conclusions}

Supports of macroporous PVDF on PP non-woven fabric have been developed and used to prepare high-flux TFC membranes with PIM-1 as the active layer. Supports were obtained with surface pore sizes in the range $25-55 \mathrm{~nm}$ and fractional surface porosities in the range $0.38-0.69$, as determined by atomic force microscopy. The addition of $3 \mathrm{wt} . \%$ phosphoric acid to the PVDF dope solution was beneficial in enhancing surface porosity while decreasing pore size. At 5 wt.\% phosphoric acid there was a further decrease in pore size, but with a slight loss of surface porosity. Optimization of the surface porosity of the support is critical to the development of high performance TFC membranes.

In pervaporation with TFC membranes of a 1-butanol/water mixture (5 wt.\%), total flux increased on decreasing the PIM-1 thickness from $2.8 \mu \mathrm{m}$ to $1.0 \mu \mathrm{m}$. However, thickness-normalised flux showed a decrease with decreasing PIM-1 thickness, suggesting that better performance should be achievable. Flux and separation factor increased with increasing feed temperature. At $65^{\circ} \mathrm{C}$, values of total flux up to $9 \mathrm{~kg} \mathrm{~m}^{-2} \mathrm{~h}^{-1}$ were obtained, with PSI values up to $112 \mathrm{~kg} \mathrm{~m}^{-2} \mathrm{~h}^{-1}$, which represents very good performance compared to most data reported in the literature. This work focussed on pure PIM-1 as the active layer. 
Further enhancements in performance can be expected with nanocomposite active layers, and that will be the focus of future work.

\section{Acknowledgments}

We are grateful to Dr. Pavel Izák, Institute of Chemical Process Fundamentals, Prague, Czech Republic, for the design of the pervaporation cell. This work was supported by EPSRC grants EP/K016946/1 and EP/M01486X/1.

Research data are provided in the supplementary information: Distributions of surface pore size of PVDF supports; water contact angles of PVDF supports; atomic force microscopy of PVDF supports; gas chromatography calibration; active layer thicknesses and pervaporation results for PIM-1/PVDF TFC membranes; pervaporation monitored over five hours.

\section{References}

[1] P.A. Kober, Pervaporation, perstillation and percrystallization, J. Amer. Chem. Soc., 39 (1917) 944-948.

[2] Y.K. Ong, G.M. Shi, L. Ngoc Lieu, Y.P. Tang, J. Zuo, S.P. Nunes, T.-S. Chung, Recent membrane development for pervaporation processes, Progr. Polym. Sci., 57 (2016) 1-31.

[3] N. Abdehagh, F.H. Tezel, J. Thibault, Separation techniques in butanol production: Challenges and developments, Biomass \& Bioenergy, 60 (2014) 222-246.

[4] K.W. Staggs, D.R. Nielsen, Improving n-butanol production in batch and semi-continuous processes through integrated product recovery, Process Biochem., 50 (2015) 1487-1498.

[5] A. Kujawska, J. Kujawski, M. Bryjak, W. Kujawski, ABE fermentation products recovery methods-A review, Renewable \& Sustainable Energy Reviews, 48 (2015) 648-661.

[6] C.J. Davey, D. Leak, D.A. Patterson, Hybrid and Mixed Matrix Membranes for Separations from Fermentations, Membranes, 6 (2016).

[7] J. Marszalek, P. Rdzanek, W. Kaminski, Improving performance of pervaporation membranes for biobutanol separation, Desalination and Water Treatment, 56 (2015) 3535-3543.

[8] G. Liu, W. Wei, W. Jin, Pervaporation Membranes for Biobutanol Production, ACS Sust. Chem. Eng., 2 (2014) 546-560.

[9] Z. Dong, G. Liu, S. Liu, Z. Liu, W. Jin, High performance ceramic hollow fiber supported PDMS composite pervaporation membrane for bio-butanol recovery, J. Membr. Sci., 450 (2014) 38-47.

[10] A. Kujawska, K. Knozowska, J. Kujawa, W. Kujawski, Influence of downstream pressure on pervaporation properties of PDMS and POMS based membranes, Sep. Purific. Technol., 159 (2016) 68-80.

[11] M. Lazarova, P. Boesch, A. Friedl, POMS Membrane for Selective Separation of Ethanol from Dilute Alcohol-Aqueous Solutions by Pervaporation, Sep. Sci. Technol., 47 (2012) 1709-1714.

[12] A. Rom, D. Esteve, A. Friedl, Organophilic Pervaporation of Butanol from an Aqueous Solution with POMS, in: P. Varbanov, J.J. Klemes, P. Seferlis, A.I. Papadopoulos, S. Voutetakis, S. Pierucci (Eds.) 16th International Conference on Process Integration, Modelling and Optimisation for Energy Saving and Pollution Reduction, 2013, pp. 1315-1320.

[13] G. Genduso, H. Farrokhzad, Y. Latre, S. Darvishmanesh, P. Luis, B. Van der Bruggen, Polyvinylidene fluoride dense membrane for the pervaporation of methyl acetate-methanol mixtures, J. Membr. Sci., 482 (2015) 128-136. 
[14] Y. Li, J. Shen, K. Guan, G. Liu, H. Zhou, W. Jin, PEBA/ceramic hollow fiber composite membrane for high-efficiency recovery of bio-butanol via pervaporation, J. Membr. Sci., 510 (2016) 338-347.

[15] S. Claes, P. Vandezande, S. Mullens, K. De Sitter, R. Peeters, M.K. Van Bael, Preparation and benchmarking of thin film supported PTMSP-silica pervaporation membranes, J. Membr. Sci., 389 (2012) 265-271.

[16] P.M. Budd, E.S. Elabas, B.S. Ghanem, S. Makhseed, N.B. McKeown, K.J. Msayib, C.E. Tattershall, D. Wang, Solution-processed, organophilic membrane derived from a polymer of intrinsic microporosity, Adv. Mater., 16 (2004) 456-459.

[17] S.V. Adymkanov, Y.P. Yampol'skii, A.M. Polyakov, P.M. Budd, K.J. Reynolds, N.B. McKeown, K.J. Msayib, Pervaporation of alcohols through highly permeable PIM-1 polymer films, Polym. Sci. Ser. A, 50 (2008) 444-450.

[18] M. Zak, M. Klepic, L.C. Stastna, Z. Sedlakova, H. Vychodilova, S. Hovorka, K. Friess, A. Randova, L. Brozova, J.C. Jansen, M.R. Khdhayyer, P.M. Budd, P. Izak, Selective removal of butanol from aqueous solution by pervaporation with a PIM-1 membrane and membrane aging, Sep. Purific. Technol., 151 (2015) 108-114.

[19] X.M. Wu, Q.G. Zhang, F. Soyekwo, Q.L. Liu, A.M. Zhu, Pervaporation removal of volatile organic compounds from aqueous solutions using the highly permeable PIM-1 membrane, AICHE J., 62 (2016) 842-851.

[20] M. Kanemoto, H. Negishi, K. Sakaki, T. Ikegami, S. Chohnan, Y. Nitta, Y. Kurusu, H. Ohta, Efficient butanol recovery from acetone-butanol-ethanol fermentation cultures grown on sweet sorghum juice by pervaporation using silicalite-1 membrane, J. Biosci. Bioeng., 121 (2016) 697-700. [21] H. Zhou, Y. Su, X. Chen, Y. Wan, Separation of acetone, butanol and ethanol (ABE) from dilute aqueous solutions by silicalite-1/PDMS hybrid pervaporation membranes, Sep. Purific. Technol., 79 (2011) 375-384.

[22] X. Wang, J. Chen, M. Fang, T. Wang, L. Yu, J. Li, ZIF-7/PDMS mixed matrix membranes for pervaporation recovery of butanol from aqueous solution, Sep. Purific. Technol., 163 (2016) 39-47.

[23] S. Liu, G. Liu, J. Shen, W. Jin, Fabrication of MOFs/PEBA mixed matrix membranes and their application in bio-butanol production, Sep. Purific. Technol., 133 (2014) 40-47.

[24] M. Alberto, J.M. Luque-Alled, L. Gao, M. Iliut, E. Prestat, L. Newman, S.J. Haigh, A. Vijayaraghavan, P.M. Budd, P. Gorgojo, Enhanced organophilic separations with mixed matrix membranes of polymers of intrinsic microporosity and graphene-like fillers, J. Membr. Sci., 526 (2017) 437-449.

[25] K.S.W. Sing, D.H. Everett, R.A.W. Haul, L. Moscou, R.A. Pierotti, J. Rouquerol, T.

Siemieniewska, Reporting physisorption data for gas/solid systems, Pure Appl. Chem., 57 (1985) 603619.

[26] P.M. Budd, B.S. Ghanem, S. Makhseed, N.B. McKeown, K.J. Msayib, C.E. Tattershall, Polymers of intrinsic microporosity (PIMs): robust, solution-processable, organic nanoporous materials, Chem. Commun., (2004) 230-231.

[27] D. Fritsch, P. Merten, K. Heinrich, M. Lazar, M. Priske, High performance organic solvent nanofiltration membranes: Development and thorough testing of thin film composite membranes made of polymers of intrinsic microporosity (PIMs), J. Membr. Sci., 401 (2012) 222-231.

[28] S. Tsarkov, V. Khotimskiy, P.M. Budd, V. Volkov, J. Kukushkina, A. Volkov, Solvent nanofiltration through high permeability glassy polymers: Effect of polymer and solute nature, J. Membr. Sci., 423 (2012) 65-72.

[29] T.S. Anokhina, A.A. Yushkin, P.M. Budd, A.V. Volkov, Application of PIM-1 for solvent swing adsorption and solvent recovery by nanofiltration, Sep. Purific. Technol., 156 (2015) 683-690.

[30] P. Gorgojo, S. Karan, H.C. Wong, M.F. Jimenez-Solomon, J.T. Cabral, A.G. Livingston, Ultrathin Polymer Films with Intrinsic Microporosity: Anomalous Solvent Permeation and High Flux Membranes, Adv. Funct. Mater., 24 (2014) 4729-4737.

[31] P.M. Budd, K.J. Msayib, C.E. Tattershall, B.S. Ghanem, K.J. Reynolds, N.B. McKeown, D. Fritsch, Gas separation membranes from polymers of intrinsic microporosity, J. Membr. Sci., 251 (2005) 263-269.

[32] P.M. Budd, N.B. McKeown, B.S. Ghanem, K.J. Msayib, D. Fritsch, L. Starannikova, N. Belov, O. Sanfirova, Y. Yampolskii, V. Shantarovich, Gas permeation parameters and other physicochemical 
properties of a polymer of intrinsic microporosity: Polybenzodioxane PIM-1, J. Membr. Sci., 325 (2008) 851-860.

[33] S. Thomas, I. Pinnau, N. Du, M.D. Guiver, Pure- and mixed-gas permeation properties of a microporous spirobisindane-based ladder polymer (PIM-1), J. Membr. Sci., 333 (2009) 125-131.

[34] S. Thomas, I. Pinnau, N. Du, M.D. Guiver, Hydrocarbon/hydrogen mixed-gas permeation properties of PIM-1, an amorphous microporous spirobisindane polymer, J. Membr. Sci., 338 (2009) $1-4$.

[35] T. Emmler, K. Heinrich, D. Fritsch, P.M. Budd, N. Chaukura, D. Ehlers, K. Ratzke, F. Faupel, Free Volume Investigation of Polymers of Intrinsic Microporosity (PIMs): PIM-1 and PIM1 Copolymers Incorporating Ethanoanthracene Units, Macromolecules, 43 (2010) 6075-6084. [36] F.Y. Li, Y. Xiao, T.-S. Chung, S. Kawi, High-Performance Thermally Self-Cross-Linked Polymer of Intrinsic Microporosity (PIM-1) Membranes for Energy Development, Macromolecules, 45 (2012) 1427-1437.

[37] F.Y. Li, Y. Xiao, Y.K. Ong, T.-S. Chung, UV-Rearranged PIM-1 Polymeric Membranes for Advanced Hydrogen Purification and Production, Advanced Energy Materials, 2 (2012) 1456-1466. [38] P. Li, T.S. Chung, D.R. Paul, Gas sorption and permeation in PIM-1, J. Membr. Sci., 432 (2013) 50-57.

[39] P. Li, T.S. Chung, D.R. Paul, Temperature dependence of gas sorption and permeation in PIM-1, J. Membr. Sci., 450 (2014) 380-388.

[40] M.M. Khan, G. Bengtson, S. Shishatskiy, B.N. Gacal, M.M. Rahman, S. Neumann, V. Filiz, V. Abetz, Cross-linking of Polymer of Intrinsic Microporosity (PIM-1) via nitrene reaction and its effect on gas transport property, Eur. Polym. J., 49 (2013) 4157-4166.

[41] R. Swaidan, B.S. Ghanem, E. Litwiller, I. Pinnau, Pure- and mixed-gas CO2/CH4 separation properties of PIM-1 and an amidoxime-functionalized PIM-1, J. Membr. Sc., 457 (2014) 95-102.

[42] Q. Song, S. Cao, P. Zavala-Rivera, L.P. Lu, W. Li, Y. Ji, S.A. Al-Muhtaseb, A.K. Cheetham, E. Sivaniah, Photo-oxidative enhancement of polymeric molecular sieve membranes, Nature Commun., 4 (2013).

[43] Q. Song, S. Cao, R.H. Pritchard, B. Ghalei, S.A. Al-Muhtaseb, E.M. Terentjev, A.K. Cheetham, E. Sivaniah, Controlled thermal oxidative crosslinking of polymers of intrinsic microporosity towards tunable molecular sieve membranes, Nature Commun., 5 (2014).

[44] C.A. Scholes, J. Jin, G.W. Stevens, S.E. Kentish, Hydrocarbon solubility, permeability, and competitive sorption effects in polymer of intrinsic microporosity (PIM-1) membranes, J. Polym. Sci. Part B-Polym. Phys., 54 (2016) 397-404.

[45] L.M. Robeson, The upper bound revisited, J. Membr. Sci., 320 (2008) 390-400.

[46] N.A. Rakow, M.S. Wendland, J.E. Trend, R.J. Poirier, D.M. Paolucci, S.P. Maki, C.S. Lyons, M.J. Swierczek, Visual Indicator for Trace Organic Volatiles, Langmuir, 26 (2010) 3767-3770.

[47] J.C. Thomas, J.E. Trend, N.A. Rakow, M.S. Wendland, R.J. Poirier, D.M. Paolucci, Optical Sensor for Diverse Organic Vapors at ppm Concentration Ranges, Sensors, 11 (2011) 3267-3280. [48] C.R. Mason, M.G. Buonomenna, G. Golemme, P.M. Budd, F. Galiano, A. Figoli, K. Friess, V. Hynek, New organophilic mixed matrix membranes derived from a polymer of intrinsic microporosity and silicalite-1, Polymer, 54 (2013) 2222-2230.

[49] F. Lipnizki, J. Olsson, P. Wu, A. Weis, G. Tragardh, R.W. Field, Hydrophobic pervaporation: Influence of the support layer of composite membranes on the mass transfer, Sep. Sci. Technol., 37 (2002) 1747-1770.

[50] K.J. Reynolds, Synthesis, characterization and proeprties of a polymer of intrinsic microporosity, in: PhD Thesis, University of Manchester, 2007.

[51] K.Y. Jee, Y.T. Lee, Preparation and characterization of siloxane composite membranes for nbutanol concentration from ABE solution by pervaporation, J. Membr. Sci., 456 (2014) 1-10.

[52] P.V. Naik, R. Bernstein, I.F.J. Vankelecom, Influence of support layer and PDMS coating conditions on composite membrane performance for ethanol/water separation by pervaporation, $\mathrm{J}$. Appl. Polym. Sci., 133 (2016).

[53] Y. Bai, L. Dong, J. Lin, Y. Zhu, C. Zhang, J. Gu, Y. Sun, Y. Xu, High performance polydimethylsiloxane pervaporative membranes with hyperbranched polysiloxane as a crosslinker for separation of n-butanol from water, RSC Adv., 5 (2015) 52759-52768. 
[54] S. Claes, P. Vandezande, S. Mullens, R. Leysen, K. De Sitter, A. Andersson, F.H.J. Maurer, H. Van den Rul, R. Peeters, M.K. Van Bael, High flux composite PTMSP-silica nanohybrid membranes for the pervaporation of ethanol/water mixtures, J. Membr. Sci., 351 (2010) 160-167.

[55] Y. Zhang, N.L. Le, T.S. Chung, Y. Wang, Thin-film composite membranes with modified polyvinylidene fluoride substrate for ethanol dehydration via pervaporation, Chem. Eng. Sci., 118 (2014) 173-183.

[56] W.D. Benzinger, D.N. Robinson, Porous vinylidene fluoride polymer membrane and process for its preparation, in: US patent 4,384,047, Pennwalt Corporation, 1983.

[57] R. Naim, A.F. Ismail, A. Mansourizadeh, Effect of non-solvent additives on the structure and performance of PVDF hollow fiber membrane contactor for CO2 stripping, J. Membr. Sci., 423-424 (2012) 503-513.

[58] A. Mansourizadeh, A.F. Ismail, Influence of membrane morphology on characteristics of porous hydrophobic PVDF hollow fiber contactors for CO2 stripping from water, Desalination, 287 (2012) 220-227.

[59] D. Hou, H. Fan, Q. Jiang, J. Wang, X. Zhang, Preparation and characterization of PVDF flatsheet membranes for direct contact membrane distillation, Sep. Purif. Technol., 135 (2014) 211-222.

[60] D. Hou, G. Dai, J. Wang, H. Fan, L. Zhang, Z. Luan, Preparation and characterization of PVDF/nonwoven fabric flat-sheet composite membranes for desalination through direct contact membrane distillation, Sep. Purif. Technol., 101 (2012) 1-10.

[61] A. Mansourizadeh, A.F. Ismail, M.S. Abdullah, B.C. Ng, Preparation of polyvinylidene fluoride hollow fiber membranes for $\mathrm{CO} 2$ absorption using phase-inversion promoter additives, J. Membr. Sci., 355 (2010) 200-207.

[62] S. Atchariyawut, C. Feng, R. Wang, R. Jiraratananon, D.T. Liang, Effect of membrane structure on mass-transfer in the membrane gas-liquid contacting process using microporous PVDF hollow fibers, J. Membr. Sci., 285 (2006) 272-281.

[63] N. Du, J. Song, G.P. Robertson, I. Pinnau, M.D. Guiver, Linear high molecular weight ladder polymer via fast polycondensation of 5,5',6,6'-tetrahydroxy-3,3,3',3'-tetramethylspirobisindane with 1,4-dicyanotetrafluorobenzene, Macromol. Rapid Commun., 29 (2008) 783-788.

[64] N. Misdan, W.J. Lau, A.F. Ismail, T. Matsuura, Formation of thin film composite nanofiltration membrane: Effect of polysulfone substrate characteristics, Desalination, 329 (2013) 9-18.

[65] R.Y.M. Huang, X.S. Feng, Dehydration of isopropanol by pervaporation using aromatic polyetherimide membranes, Sep. Sci. Technol., 28 (1993) 2035-2048.

[66] A. Mansourizadeh, A.F. Ismail, Preparation and characterization of porous PVDF hollow fiber membranes for $\mathrm{CO} 2$ absorption: Effect of different non-solvent additives in the polymer dope, Int. J. Greenhouse Gas Control, 5 (2011) 640-648.

[67] M.J. Han, S.T. Nam, Thermodynamic and rheological variation in polysulfone solution by PVP and its effect in the preparation of phase inversion membrane, J. Membr. Sci., 202 (2002) 55-61. [68] S. Singh, K.C. Khulbe, T. Matsuura, P. Ramamurthy, Membrane characterization by solute transport and atomic force microscopy, J. Membr. Sci., 142 (1998) 111-127.

[69] S.-Y. Li, R. Srivastava, R.S. Parnas, Separation of 1-butanol by pervaporation using a novel trilayer PDMS composite membrane, J. Membr. Sci., 363 (2010) 287-294.

[70] A.G. Fadeev, Y.A. Selinskaya, S.S. Kelley, M.M. Meagher, E.G. Litvinova, V.S. Khotimsky, V.V. Volkov, Extraction of butanol from aqueous solutions by pervaporation through poly(1trimethylsilyl-1-propyne), J. Membr. Sci., 186 (2001) 205-217.

[71] K. Srinivasan, K. Palanivelu, A.N. Gopalakrishnan, Recovery of 1-butanol from a model pharmaceutical aqueous waste by pervaporation, Chem. Eng. Sci., 62 (2007) 2905-2914.

[72] D.-G. Kim, T. Takigawa, T. Kashino, O. Burtovyy, A. Bell, R.A. Register, Hydroxyhexafluoroisopropylnorbornene Block and Random Copolymers via Vinyl Addition Polymerization and Their Application as Biobutanol Pervaporation Membranes, Chem. Mater., 27 (2015) 6791-6801.

[73] M. Hu, S. Tang, W. Fu, L. Gao, X. Liu, Y. Luo, C. Huang, Vinyl-modified hyperbranched polyether cross-linked hydroxyl-terminated polybutadiene-based polyurethane membrane for pervaporation recovery of butanol, High Perform. Polym., 27 (2015) 381-391.

[74] X.S. Feng, R.Y.M. Huang, Concentration polarization in pervaporation separation processes, J. Membr. Sci., 92 (1994) 201-208. 
[75] Y. Huang, D.R. Paul, Effect of film thickness on the gas-permeation characteristics of glassy polymer membranes, Industrial \& Engineering Chemistry Research, 46 (2007) 2342-2347.

[76] A. Yushkin, A. Grekhov, S. Matson, M. Bermeshev, V. Khotimsky, E. Finkelstein, P.M. Budd, V. Volkov, T.J.H. Vlugt, A. Volkov, Study of glassy polymers fractional accessible volume (FAV) by extended method of hydrostatic weighing: Effect of porous structure on liquid transport, React. Funct. Polym., 86 (2015) 269-281.

[77] A. Rozicka, J. Niemisto, R.L. Keiski, W. Kujawski, Apparent and intrinsic properties of commercial PDMS based membranes in pervaporative removal of acetone, butanol and ethanol from binary aqueous mixtures, J. Membr. Sci., 453 (2014) 108-118. 